\title{
Mercury accumulation in marine fish most favoured by Malaysian women, the predictors and the potential health risk
}

\begin{abstract}
We identified marine fish species most preferred by women at reproductive age in Selangor, Malaysia, mercury concentrations in the fish muscles, factors predicting mercury accumulation and the potential health risk. Nineteen most preferred marine fish species were purchased $(n=175)$ from selected fisherman's and wholesale market. Length, weight, habitat, feeding habit and trophic level were recognised. Edible muscles were filleted, dried at $80{ }^{\circ} \mathrm{C}$, ground on an agate mortar and digested in Multiwave 3000 using $\mathrm{HNO}_{3}$ and $\mathrm{H}_{2} \mathrm{O}_{2}$. Total mercury was quantified using VP90 cold vapour system with $\mathrm{N}_{2}$ carrier gas. Certified reference material DORM-4 was used to validate the results. Fish species were classified as demersal (7) and pelagic (12) or predators (11), zoo benthos (6) and planktivorous (2). Length, weight and trophic level ranged from 10.5 to $75.0 \mathrm{~cm}, 0.01$ to $2.50 \mathrm{~kg}$ and 2.5 to 4.5 , respectively. Geometric mean of total mercury ranged from 0.21 to $0.50 \mathrm{mg} / \mathrm{kg}$; maximum in golden snapper $(0.90 \mathrm{mg} / \mathrm{kg})$. Only $9 \%$ of the samples exceeded the JECFA recommendation. Multiple linear regression found demersal, high trophic $(\geq 4.0)$ and heavier fishes to accumulate more mercury in muscles $\left(R^{2}=27.3 \%\right)$, controlling for all other factors. About $47 \%$ of the fish samples contributed to mercury intake above the provisional tolerable level $(45 \mu \mathrm{g} /$ day). While only a small portion exceeded the JECFA fish $\mathrm{Hg}$ guideline, the concentration reported may be alarming for heavy consumers. Attention should be given in risk management to avoid demersal and high trophic fish, predominantly heavier ones.
\end{abstract}

Keyword: Marine fish; Mercury; Malaysia; Predictors; Fish characteristics; Linear regression; Health risk 